\title{
SYNTHETIC CHALCONES CYTOTOXIC ACTIVITY ON EHRLICH ASCITIC TUMOR CELLS (MURINE BREAST CANCER)
}

Eliane B. Nunes ${ }^{1,2 *}$, Aline Bernardes ${ }^{3}$, Caridad Noda-Perez ${ }^{3}$, Stanislau P. Cardozo1, Hugo D. Silva², Ingrid O. Travassos², Paula F. F. Silva², Elisângela P. Silveira-Lacerda²

${ }^{1}$ Programa de Pós-graduação em Inovação Farmacèutica, Faculdade de Farmácia, Universidade Federal de Goiás (UFG) Goiânia (GO), Brazil.

²Laboratório de Genética Molecular e Citogenética, Instituto de Ciências Biológicas, UFG - Goiânia (GO), Brazil.

${ }^{3}$ Instituto de Química, Instituto de Química, UFG - Goiânia (GO), Brazil.

*Corresponding author: ebnunes@gmail.com

Breast cancer is the world leading cause of women death. The chemotherapy has presented several side effects and many cases of chemo-resistence. Thus, research of new antineoplasic molecules with less aggressive effects is necessary. Chalcones have demonstrated extensive pharmacological potential including antineoplasic. Objective: The aim of this study was to evaluate in vitro cytotoxic effect induced for synthetic chalcones CLF and DMF on Ehrlich Ascitic Tumor (TAE) cells of murinho mammary carcinoma, by MTT (3-(4,5-dimethylthiazol-2- yl)-2,5diphenyltetrazolium bromide) colorimetric assay as described by Mosman (1983). Methodology: The compounds CLF and DMF were solubilized in dimethilsulfoxide $1 \%$. TAE cells were colected from Murine peritoneal cavity, washed with PBS and maintained in $5 \% \mathrm{CO} 2$ for $24 \mathrm{~h}$ at $37^{\circ} \mathrm{C}$ in humidified atmosphere. After, RPMI-1640 medium was supplemented with $10 \% \mathrm{FBS}, 1 \%$ penicillin/streptomycin and $0.3 \%$ amphotericin. The $1.0 \times 105 \mathrm{TAE}$ cells were plated in 96-well tissue culture plates and treated with different concentrations of CLF and DMF (0.2, 2.0, 20, 50, 100 and $200 \mu \mathrm{M}$ ) for $48 \mathrm{~h}$. After treatment, $10 \mu \mathrm{L}$ of MTT ( $5 \mathrm{mg} . \mathrm{mL}-1)$ was added to each well, and the plates were incubated at $37^{\circ} \mathrm{C}$ for $3 \mathrm{~h}$. The purple formazan crystals were dissolved in $50 \mu \mathrm{L}$ of SDS (dodecyl sulfate sodium), and the absorbance was determined at $545 \mathrm{~nm}$. The cell viability was calculated: viability (\%) =_ (absorbance of the treated wells)/(absorbance of the control wells) $\times 100$. The tests were performed in triplicates and IC50 (concentration $(\mu \mathrm{M})$ that results in a $50 \%$ reduction in cellular viability) was obtained from sigmoidal dose-response curves (nonlinear regression) using the software GraphPad Prism 5.0 for Windows. Results: The chalconas CLF and DMF presented a statistically significant cytotoxic effect inducing cell death in a dose dependent manner. The chalcones inhibit TAE cells viability with an estimated IC50 of $22.30 \pm 5.10 \mu \mathrm{M}$ and $46.30 \pm 6.10 \mu \mathrm{M}$, respectively at $48 \mathrm{~h}$ of treatment, by nonlinear regression curve. Conclusions: The chalconas exhibits significant cytotoxicity in $48 \mathrm{~h}$ against TAE cells. The CLF was more potent than DMF, but both results showed important dose-dependent biological property of chalconas. Therefore, future studies will be necessary to identify the molecular mechanisms where compound operates. 